\title{
Developmental changes of fluconazole clearance in neonates and infants in relation to ontogeny of glomerular filtration rate: literature review and data analysis
}

Kazutoshi Murakoso ${ }^{1,2^{*}}$, Ryoichi Minagawa ${ }^{2}$ and Hirotoshi Echizen ${ }^{1}$

\begin{abstract}
Background: Fluconazole is frequently prescribed for the treatment of systemic fungal infection in neonates and infants. At present, prediction of fluconazole doses according to developmental changes in fluconazole clearance is not being done in these patients. We aimed to formulate a developmental model of fluconazole clearance taking into account the ontogeny of renal function, since the drug is largely eliminated renally.
\end{abstract}

Methods: We systematically retrieved the data of fluconazole pharmacokinetics and renal function in children and adults from databases (MEDLINE and Japan Medical Abstracts Society). Datasets were retrieved from individual children or groups from 9 studies comprising 55 neonates or infants at postmenstrual age (PMA) 27-58 weeks. Datasets were retrieved from 5 studies comprising 60 children and from 13 studies comprising 152 adults. Datasets of glomerular filtration rate (GFR) for individual pediatric subjects were retrieved from 4 studies comprising 187 neonates or infants.

Results: Fluconazole clearance normalized to body surface area (BSA) $\left(\mathrm{CL}_{B S A}\right)$ in neonates was $1 / 3$ to $1 / 4$ of adult values, but $C_{B S A}$ increased rapidly during the neonatal and infantile periods and attained near adult values at PMA 60 weeks. A significant correlation between $\mathrm{CL}_{B S A}$ and PMA was observed in neonates and infants: $\mathrm{CL}_{B S A}(\mathrm{~mL} / \mathrm{min} /$ $\left.\mathrm{m}^{2}\right)=0.26$ PMA (weeks) $-4.9(r=0.68, p<0.001)$. In addition, the developmental time course of GFR normalized to BSA (GFR $R_{B S A}$ ) was fitted well to a sigmoidal model with the maximum GFRBSA of $149 \mathrm{~mL} / \mathrm{min} / 1.73 \mathrm{~m}^{2}$, PMA associated with $50 \%$ of GFR $\mathrm{BSA}_{\mathrm{max}}\left(\mathrm{PMA}_{50}\right)$ of 54 weeks, and the Hill coefficient of 3.7. A significant correlation between fluconazole clearance and GFR was found in neonates and infants: $\mathrm{CL}(\mathrm{mL} / \mathrm{min})=0.34 \mathrm{GFR}(\mathrm{mL} / \mathrm{min})-0$. $53(r=0.84, p<0.001)$. Assuming that plasma drug concentrations required for treating fungal infection are comparable between children and adults, fluconazole doses for pediatric patients with given PMAs may be predicted from adult doses (such as $100 \mathrm{mg} /$ day) using size-normalized clearance as a scaling factor. The predicted doses for neonates and infants were largely within the ranges recommended in the prescribing information.

Conclusions: The present study indicates that fluconazole doses for neonates and infants may be predicted from developmental change of systemic clearance, the ontogeny of which parallels the maturation of nephron function.

Keywords: Neonates, Infants, Postmenstrual age, Fluconazole, Pharmacokinetics, Ontogeny, Glomerular filtration rate

\footnotetext{
* Correspondence: kazu_murakoso@yahoo.co.jp

${ }^{1}$ Department of Pharmacotherapy, Meiji Pharmaceutical University, 2-522-1

Noshio, Kiyose, Tokyo 204-8588, Japan

2Department of Hospital Pharmacy, Soka Municipal Hospital, 2-21-1 Soka,

Saitama 340-8560, Japan
} 


\section{Background}

Numerous studies have been conducted to establish a comprehensive dosing formula for neonates, infants, and children who undergo tremendous developmental changes in pharmacokinetics and pharmacodynamics [1]. Recently, Anderson and Holford [2] reported that adult doses may be scaled down to pediatric doses using a child/adult body surface area (BSA) ratio or an allometric scaling factor (exponent of $3 / 4$ of the child/adult body weight ratio) for children older than 2 or 3 years, but additional factor of maturation should also be taken into account for neonates and infants. However, whether the above approaches work well in predicting fluconazole doses for neonates and infants remains largely unknown.

Fluconazole is a triazole antifungal agent frequently used for the treatment of systemic candidiasis or cryptococcosis in pediatric patients including neonates and infants, at doses of 3 to $6 \mathrm{mg} / \mathrm{kg}$ [3]. However, these dosing schemes are largely empirical and are not supported by pharmacokinetic data. At present, no dosing formula has been established for estimating fluconazole doses considering developmental changes of systemic clearance $(\mathrm{CL})$ of fluconazole.

With this background, we aimed to study the developmental time courses of fluconazole CL and glomerular filtration rate (GFR) as a function of postmenstrual age (PMA) in pediatric patients, using datasets retrieved systematically from relevant patient populations and adults using databases in English (MEDLINE) and Japanese (Japan Medical Abstract Society). Furthermore, we aimed to formulate an equation to estimate fluconazole doses for pediatric patients as a function of PMA by combining the relationship between $\mathrm{CL}$ and GFR and that between GFR and PMA in children. Here, we present the data indicating that fluconazole doses for neonates and infants may be predicted by our formula by comparing with the doses predicted using empirical formulas of Augsberger [4] and Crawford [5] as well as those recommended in the current prescribing information [3].

\section{Methods}

\section{Search for pharmacokinetic data of fluconazole}

We searched for studies on fluconazole pharmacokinetics performed in premature and full-term neonates, infants, children, and adults in the MEDLINE database using at a combination of the following keywords: "UK49858 OR fluconazole" AND "child* OR pediatric* OR infant* OR neonate* OR premature ${ }^{*}$ " AND "pharmacokinetic*". Additionally, we searched for relevant studies performed in adults using keywords of "UK49858 OR fluconazole" AND adult* AND pharmacokinetic*. We also searched for relevant studies reported in Japanese in the database operated by Japan Medical Abstracts Society, using the same set of keywords in Japanese. We also searched for the articles cited in the retrieved literature. We collected CL of fluconazole in studies in which the drug was administered intravenously. In articles that did not report CL but included data of area under the curve from time 0 to infinity $\left(\mathrm{AUC}_{0 \text {-inf }}\right)$ after intravenous injection, we calculated $\mathrm{CL}$ by dividing $\mathrm{AUC}_{0 \text {-inf }}$ by the corresponding doses. When plasma concentration-time data were available after oral administration, systemic clearance was estimated by assuming that oral bioavailability of the drug was $94 \%$, as reported elsewhere [6]. When only AUC from time 0 to $24 \mathrm{~h}\left(\mathrm{AUC}_{0-24}\right)$ were available, AUC were estimated by adding $\mathrm{AUC}_{24-\infty}$ estimated by extrapolation from concentration measured at $24 \mathrm{~h}$ and the elimination constant.

\section{Developmental changes of fluconazole clearance and GFR as a function of PMA}

Fluconazole $\mathrm{CL}$ in pediatric patients retrieved from the literature were size-corrected or normalized to body weight $(\mathrm{BW})$ and body surface area (BSA) $\left(\mathrm{CL}_{\mathrm{BW}}\right.$ and $\mathrm{CL}_{\mathrm{BSA}}$, respectively) as scaling factors for each patient. In the literature, individual body weights were available for most of the full-term neonates, but heights were available from approximately 30\% of them. For nonJapanese neonates or infants at PMA 40 weeks or older without individual height data, the 50 percentile height for the corresponding chronological age according to the WHO growth chart for boys was used [7]. For Japanese infants, the growth chart for Japanese boys was used [8]. For most premature neonates, however, individual body weights and heights were not available in the literature. Their body weights and heights were estimated using Ahn's data table that lists the average values based on the records of 5014 premature infants [9], irrespective of ethnicity.

BSA for full-term infants was estimated according to the formula of Haycock et al. [10] as follows:

$$
\begin{aligned}
\operatorname{BSA}\left(\mathrm{m}^{2}\right) & =\text { weight }(\mathrm{kg})^{0.5378} \times \text { height }(\mathrm{cm})^{0.3964} \\
& \times 0.024265
\end{aligned}
$$

For children and adults whose individual body weights and heights were available, BSA was estimated according to the formula of DuBois and DuBois [11].

$$
\begin{aligned}
\operatorname{BSA}\left(\mathrm{m}^{2}\right)= & \text { weight }(\mathrm{kg})^{0.425} \times \text { height }(\mathrm{cm})^{0.725} \\
& \times 0.07184
\end{aligned}
$$

In 13 articles on adult patients, the data of heights and weights were available in three articles comprising 39 individual patients. BSA of the respective patients were calculated using Eq. 2. In four articles, only mean heights and weights for the study populations were 
available. In these cases, group BSA was calculated using Eq. 2. In the remaining 6 articles, no height and weight data were available. In these cases, we assumed that the patients had standard body weight $(63 \mathrm{~kg})$ and height $(170 \mathrm{~cm})$, and hence BSA of $1.73 \mathrm{~m}^{2}$.

Developmental changes of fluconazole CL in premature and full-term neonates at PMA 60 weeks or younger were analyzed by a linear regression model as a function of PMA. For children aged above 5 years and adults, a linear regression model was used for the analysis using chronological age.

\section{Developmental model for GFR}

We searched for articles that reported individual GFR and demographic data (body weight and height) of neonates or infants. While individual body weights were available for all subjects, heights were unavailable in 3 of 4 articles. Therefore, for the analysis on the development of GFR, we estimated BSA according to the Neo-BSA formula reported by Ahn [9].

$$
\text { BSA }\left(\mathrm{cm}^{2}\right)=10.602 \times \text { Weight }(\mathrm{g})^{0.6561}
$$

Retrieved GFR (unadjusted for size) and GFR normalized to BSA $\left(\mathrm{GFR}_{\mathrm{BSA}}\right)$ were fitted to a sigmoidal hyperbolic model as a function of PMA using the non-linear least squares regression method.

$$
G F R_{(t)}=\frac{G F R_{\max } \cdot \mathrm{PMA}^{n}}{P M A^{n}+P M A_{50}{ }^{n}}
$$

where $\mathrm{GFR}_{(\mathrm{t})}$ is GFR at a given PMA, GFR $\mathrm{max}_{\max }$ is the maximum GFR, $\mathrm{PMA}_{50}$ is the PMA associated with $50 \%$ of $G R_{\max }$, and $n$ is the Hill coefficient indicating the steepness of the curve. We used this equation to estimate GFR of pediatric patients with fluconazole CL retrieved from the literature, since a previous study [12] showed that the developmental changes of GFR as a function of PMA were fitted well to the sigmoidal model.

\section{Comparisons of fluconazole doses for neonates and infants estimated by empirical formulas with those predicted by the present $\mathrm{CL}$-based formulas and those in prescribing information}

We assumed that fluconazole $\mathrm{CL}$ in a representative adult is $0.23 \mathrm{~mL} / \mathrm{min} / \mathrm{kg}$ [13] and the corresponding standard daily dose of the drug is $100 \mathrm{mg}$ daily for most systemic fungal infections [3]. Also assuming that average plasma concentrations required for eliminating susceptible pathogens are largely similar between adults and children, we estimated fluconazole doses for neonates and infants with PMA $28-60$ weeks by multiplying the standard adult dose $(100 \mathrm{mg} /$ day $)$ by a ratio of fluconazole $\mathrm{CL}$ estimated for a given child to that of the representative adult. Fluconazole CL for a child was estimated by multiplying fluconazole $\mathrm{CL}_{\mathrm{BW}}$ or $\mathrm{CL}_{\mathrm{BSA}}$ at a given PMA by the corresponding mean BW or BSA. Fluconazole $\mathrm{CL}_{\mathrm{BW}}$ or $\mathrm{CL}_{\mathrm{BSA}}$ at a given PMA was estimated using the linear regression equation for the corresponding CL as a function of PMA. Heights and body weights of infants at PMA older than 40 weeks (full-term neonates) were substituted by the corresponding 50 percentile values obtained from the WHO growth chart [7]. Heights and body weights of infants at PMA younger than 40 weeks (premature neonates) were estimated according to Ahn's table [9] containing mean values for the respective PMA.

We estimated pediatric doses of fluconazole at PMA 28-60 weeks using two empirical formulas $[4,5]$ as follows:

$$
\begin{aligned}
\text { Augsberger's formula: Dose } & =\frac{\text { weight }(\mathrm{kg}) \times 1.5+10}{100} \\
& \times \text { adult dose }
\end{aligned}
$$

$$
\text { Crawford's formula : Dose }=\frac{B S A\left(m^{2}\right)}{1.73} \times \text { adult dose }
$$

We also calculated the recommended doses of the drug according to the descriptions in the current prescribing information [3]. Specifically, daily doses of $3 \mathrm{mg} / \mathrm{kg}$ and 3 to $6 \mathrm{mg} / \mathrm{kg}$ are recommended for the treatment of systemic candidiasis and cryptococcosis, respectively, for infants and children older than 1 month. However, neonates younger than 2 weeks and those aged 3-4 weeks are recommended to receive the same daily doses of the drug as in older children, but every 72 and $48 \mathrm{~h}$, respectively. The current prescribing information for fluconazole does not contain dose recommendation for premature neonates [3]. We calculated the daily doses of fluconazole according to these recommendations for neonates and infants younger than PMA 60 weeks.

\section{Statistical analysis}

All statistical analyses were conducted using JMP Pro (ver. 12.2.0, SAS Institute Inc. USA). Correlation between fluconazole CL and PMA in neonates and infants, and correlation between drug CL and chronological age in children and adults were analyzed by the least-squares linear regression. Non-linear least square regression method was used to analyze the sigmoidal hyperbolic model between GFR and PMA for neonates and infants. A $p$ value less than 0.05 was considered significant. 


\section{Results}

Developmental changes of pharmacokinetic parameters of fluconazole in pediatric and adult patients

Forty-two pharmacokinetic datasets of 55 neonates or infants at PMA 27-58 weeks were obtained from the literature [14-22] (Table 1). While the information about the countries where the studies were conducted is available, no information was given in literature regarding the ethnicity of the patients. In some studies [14, 18, 20], only means or ranges for the group were available. Saxen et al. [14] conducted pharmacokinetic studies in 7 patients: 3 times for 4 patients and twice for 3 patients at $6 \mathrm{mg} / \mathrm{kg}$. Nahata et al. [21], conducted pharmacokinetic studies in 2 patients by intravenous and oral administrations 1 week apart and in 4 patients only by an oral administration. Wenzl et al. [22] studied pharmacokinetics of the drug in one patient twice with different doses. Collectively, the doses of fluconazole studied were 3$6 \mathrm{mg} / \mathrm{kg}$ for oral administration and 2-25 mg/kg for intravenous administration. There were large interindividual differences in elimination half-life $\left(t_{1 / 2}\right)$ and CL: $t_{1 / 2}$ ranged from 10.7 to $88.6 \mathrm{~h}$ and $\mathrm{CL}$ normalized to body weight $\left(\mathrm{CL}_{\mathrm{BW}}\right)$ ranged from 0.16 to $1.18 \mathrm{~mL} /$ $\mathrm{min} / \mathrm{kg}$.

Sixteen pharmacokinetic datasets were retrieved from 60 children aged from 0.3 to 18.3 years (Table 2) [20, 23-26]. Specifically, Fujii et al. [20] reported the results of a multicenter clinical trial of fluconazole in which the drug was administered to 72 children and antimicrobial effects were studied. In their report, the pharmacokinetics of the drug intravenously or orally administered at different doses $(3,6$, and $12 \mathrm{mg} / \mathrm{kg})$ was studied in 7 neonates and 17 children, but only mean pharmacokinetic parameters for patients who received the same dose via the same route were available. In the study of Seay et al. [25], each child received the drug by intravenous and oral administrations and the data obtained from both routes were fitted to a pharmacokinetic model simultaneously. No data were available from children aged from 2 to 4 years. There was large inter-individual variability in the PK data: $t_{1 / 2}$ ranged from 11.9 to $42.3 \mathrm{~h}$.

For adults, 60 pharmacokinetic datasets were retrieved from those aged from 18 to 65 years (103 healthy volunteers, 32 patients with AIDS, 9 patients with vaginal candidiasis, and 8 patients with burn) [27-39]. In the reports of Shiba et al. [27] and DeMuria et al. [36], all patients received the drug by intravenous and oral routes on different occasions, For these patients, only the pharmacokinetic data obtained after an intravenous administration were included in analysis. In the report of Ripa et al. [28], 18 patients were allocated to 3 groups ( $n=6$ each) and received the drug at different doses: 50 or $150 \mathrm{mg}$ orally, or $100 \mathrm{mg}$ intravenously. We calculated fluconazole CL from plasma concentration-time data obtained after oral administration assuming that the oral bioavailability of fluconazole was 94\% [6]. Doses employed for oral administration were from 25 to $200 \mathrm{mg}$ and those for intravenous administration were from 25 to $400 \mathrm{mg}$. $\mathrm{T}_{1 / 2}$ ranged from 14.4 to $75.2 \mathrm{~h}$; $\mathrm{CL}$ ranged from 8.8 to $26.2 \mathrm{~mL} / \mathrm{min}$; and $\mathrm{CL}_{\mathrm{BW}}$ ranged from 0.19 to $0.63 \mathrm{~mL} / \mathrm{min} / \mathrm{kg}$ (Table 2).

Table 1 Pharmacokinetic parameters of fluconazole in neonates and infants

\begin{tabular}{|c|c|c|c|c|c|c|c|c|c|c|}
\hline Reference & $\mathrm{N}$ & Country & PMA (weeks) & Dose (mg/kg) & Route & $\mathrm{AUC}_{(0-\infty)}(\mu \mathrm{g}$ & $\mathrm{h} / \mathrm{mL})$ & $t_{1 / 2}(h)$ & $\mathrm{Vd}(\mathrm{L} / \mathrm{kg})$ & $\mathrm{CL}_{\mathrm{BW}}(\mathrm{mL} / \mathrm{min} / \mathrm{kg})$ \\
\hline Saxen et al. [14] & 7 & Finland & $\begin{array}{l}27 \\
28 \\
29^{a}\end{array}$ & 6 & IV & NA & & $55.2-88.6$ & $1.18-2.25$ & $0.18-0.52$ \\
\hline Krzeska et al. [15] & 14 & Poland & $41-58$ & 3 & IV & $42.3-156.0$ & & $10.7-41.8$ & $0.76-2.60$ & $0.32-1.18$ \\
\hline Kondo et al. [16] & 4 & Japan & $27-33$ & 2 & IV & NA & & $46.2-49.4$ & $1.07-1.35$ & $0.25-0.33$ \\
\hline Seki et al. [17] & 6 & Japan & $29-42$ & 3 & IV & $56.7-90.9$ & & $31.6-52.6$ & $0.57-1.01$ & NA \\
\hline Piper et al. [18] & 8 & USA & $39^{b}$ & $\begin{array}{l}25 \text { (loading) } \\
12 \text { (maintenance) }\end{array}$ & IV & $\begin{array}{l}479.0^{b} \\
347-496^{c}\end{array}$ & & $\begin{array}{l}56^{b} \\
26-80^{c}\end{array}$ & $\begin{array}{l}1.05^{b} \\
0.86-1.46^{c}\end{array}$ & $\begin{array}{l}0.27^{b} \\
0.22-0.35^{c}\end{array}$ \\
\hline Wiest et al. [19] & 1 & USA & 32 & 6 & IV & NA & & 37.4 & 1.2 & 0.33 \\
\hline Fujii et al. [20] & $\begin{array}{l}6 \\
1\end{array}$ & Japan & $40-44$ & 3 & $\begin{array}{l}\text { IV } \\
\text { PO }\end{array}$ & $\begin{array}{l}72.1^{b} \\
54.0^{b}\end{array}$ & & $\begin{array}{l}37.4^{b} \\
41.2\end{array}$ & $\begin{array}{l}0.81^{b} \\
0.99\end{array}$ & NA \\
\hline Nahata et al. [21] & $\begin{array}{l}2^{d} \\
6\end{array}$ & USA & $30-43$ & 6 & $\begin{array}{l}\text { IV } \\
\mathrm{PO}\end{array}$ & $\begin{array}{l}340.8,425.3 \\
340.5-636.1\end{array}$ & & NA & NA & $0.16-0.29$ \\
\hline Wenzl et al. [22] & 2 & Germany & $36-56$ & $4-6$ & $\mathrm{PO}$ & 162.0-233.0 & & $27.0-45.0$ & $1.21-1.88$ & NA \\
\hline
\end{tabular}

$N$ number of patients, PMA post-menstrual age, $N A$ not available, $A U C$ area under the curve, $t_{1 / 2}$ half-life, $V d$ volume of distribution, $C L_{B W}$ clearance normalized to body weight

In the study of Saxen et al. [14], data were given as ranges of means for patients who received fluconazole at different PMA. In the studies of Fujii et al. [20] and Piper et al. [18], data were given as mean for individual groups. In the studies of Krzeska et al. [15], Kondo et al. [16], Seki et al. [17], Nahata et al. [21] and Wenzl et al. [22], data were given as ranges for individual patients' values

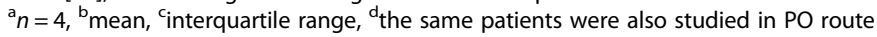




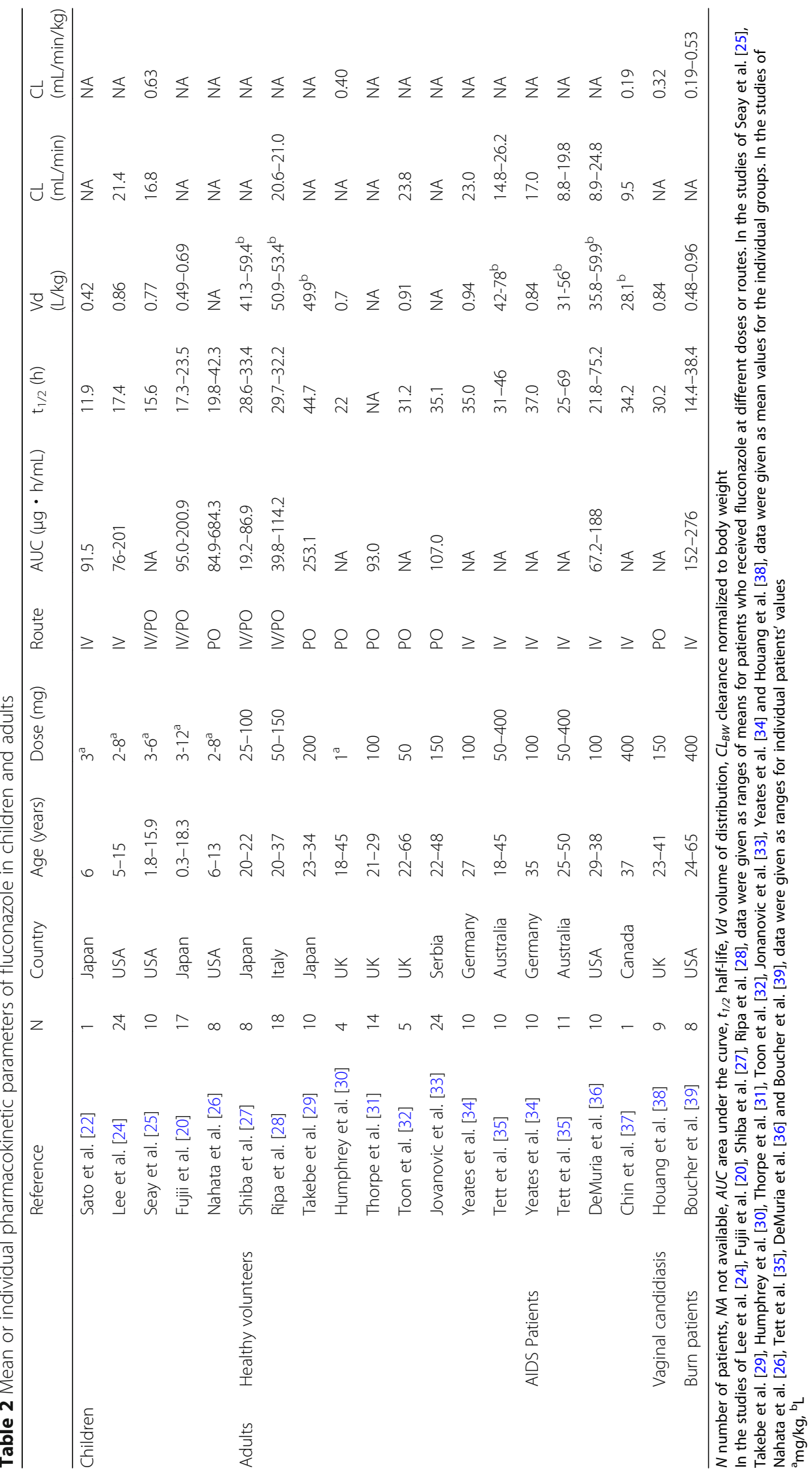


Relationship between fluconazole $\mathrm{CL}$ and PMA in neonates and infants compared to that in children and adults

While fluconazole CL in neonates and infants was much lower than that in children older than 5 years and adults due mainly to smaller body size, there was a significant positive correlation between fluconazole CL and PMA in neonates and infants (Fig. 1a): $Y=0.093 \mathrm{X}-2.45, r=0.81$ $(p<0.001)$. A significant correlation between fluconazole $\mathrm{CL}$ and age was also observed in young children and adults (Fig. 1b): $Y=0.154 \mathrm{X}+14.74, r=0.36(p<0.005)$.

To evaluate the development of fluconazole CL in size-adjusted values in subjects ranging from neonates to adults having different body sizes, we normalized fluconazole $\mathrm{CL}$ to BSA ( $\left.\mathrm{CL}_{\mathrm{BSA}}\right)$ and body weight $\left(\mathrm{CL}_{\mathrm{BW}}\right)$. $\mathrm{CL}_{\mathrm{BSA}}$ in neonates was $1 / 3$ to $1 / 4$ of that in adults, but it increased rapidly after birth and reached largely the adult values at PMA 60 weeks (approximately 5 months postpartum) (Fig. 2a). There was a significant positive correlation between $\mathrm{CL}_{\mathrm{BSA}}$ and PMA in neonates and infants: $\mathrm{CL}_{\mathrm{BSA}}: Y=0.263 \mathrm{X}-4.92, r=0.68(p<0.001)$. In contrast, a significant negative correlation between $\mathrm{CL}_{\mathrm{BSA}}$ and chronological age was found in children older than 5 years and adults (Fig. 2b): $Y=-0.097 \mathrm{X}+$ 14.22, $r=-0.36(p<0.005)$.

Fluconazole $\mathrm{CL}_{\mathrm{BW}}$ in neonates was comparable to that in adults (Fig. 3a). There was also a significant correlation between $\mathrm{CL}_{\mathrm{BW}}$ and PMA $(Y=0.011 \mathrm{X}-0.04, r=0.46$, $p<0.005)$, and $\mathrm{CL}_{\mathrm{BW}}$ at PMA 60 weeks apparently increased to a level exceeding the adult values (Fig. 3a). In contrast, there was a significant negative correlation between $\mathrm{CL}_{\mathrm{BW}}$ and age in children older than 5 years and adults (Fig. 3b): $Y=-0.006 \mathrm{X}+0.50, r=-0.60(p<0.001)$.

\section{Ontogeny of GFR in neonates to young children}

A total of 187 relevant datasets of GFR and age in children, spanning premature neonates through children aged 12 years, were retrieved from the articles of Rubin et al. [40], Fawer et al. [41], Coulthard [42] and van der Heijden et al. [43]. Briefly, Rubin et al. [40] reported individual data of GFR and age for 63 pediatric patients with chronological ages ranging from 2 days to 12 years and body weights ranging from 2.4 to $35.5 \mathrm{~kg}$. They measured GFR by mannitol clearance. We assumed that no premature neonates were studied in their study, since there were no descriptions in the article suggesting premature labor and all neonates had gestational ages of 40 weeks or longer. Fawer et al. [41] studied GFR in 44 pediatric patients having gestational ages ranging from 28 to 43 weeks (postpartum ages from 0.5 to 19 days) and body weights at birth ranging from 1.1 to $5.38 \mathrm{~kg}$. They measured GFR by inulin clearance. Coulthard [42] studied GFR in 39 pediatric patients with gestational ages ranging from 27 to 40 weeks (chronological ages from 2 to 33 days) and body weights ranging from 0.85 to $3.85 \mathrm{~kg}$. They measured GFR by inulin clearance. Van der Heijden et al. [43] studied GFR in 41 pediatric patients with gestational ages ranging from 27 to 36 weeks (chronological ages from 3 to 11 days) and body weights at birth ranging from 0.81 to $2.74 \mathrm{~kg}$. They measured GFR by inulin clearance. Individual body weights and heights of full-term infants were available in the article of Rubin et al. [40], whereas only individual body heights were available in the other articles [41-43]. Therefore, we decided to estimate BSA for these pediatric subjects using Ahn's equation (Eq. 3).

Developmental changes of GFR and GFR $_{\mathrm{BSA}}$ analyzed as a function of PMA are shown in Fig. $4 a$ and b, respectively. By fitting the retrieved datasets to a sigmoidal hyperbolic function model, we obtained the following parameters. For the GFR-PMA relationship, GFR max $_{\text {max }}$ was $70 \mathrm{~mL} / \mathrm{min}$; $\mathrm{PMA}_{50}$ was 113 weeks; and Hill coefficient was 2.5 (Fig. 4a). For the GFR $_{\mathrm{BSA}}-\mathrm{PMA}$ relationship, GFR BSAmax $_{\text {was }} 149 \mathrm{~mL} / \mathrm{min} / 1.73 \mathrm{~m}^{2}$; $\mathrm{PMA}_{50}$ was 54 weeks; and Hill coefficient was 3.7 (Fig. 4b).

\section{Relationship between fluconazole CL and GFR in neonates and infants}

A significant correlation was observed between fluconazole CL and GFR in neonates and infants: $Y=0.34 \mathrm{X}-$ 0.53, $r=0.84, p<0.001$ (Fig. 5). Since we have shown that GFR in a neonate or infant at a given PMA can be estimated using the sigmoidal hyperbolic equation (Fig. 4), fluconazole $\mathrm{CL}$ for the corresponding neonate or infant may be estimated by substituting his or her GFR into the regression equation shown in Fig. 5.

\section{Comparisons between fluconazole doses for neonates and infants predicted using empirical formulas and using CL-based formulas in reference to recommended doses in prescribing information}

Compared to the daily doses of fluconazole recommended in the prescribing information for neonates and infants [3], Augsberger's and Crawford's formulas appeared to overestimate the doses for neonates at PMA 40-42 weeks, and appeared to underestimate the doses for infants at PMA 52 weeks and older (Fig. 6). In contrast, daily doses of fluconazole for neonates and infants predicted by our CL-based method were essentially within the doses recommended by the prescribing information for infants at PMA 40-60 weeks. For premature neonates, the doses predicted by our method was approximately $50 \%$ smaller than those predicted by the 2 empirical formulas.

\section{Discussion}

To the best of our knowledge, the present study is the first to demonstrate significant increases in size- 

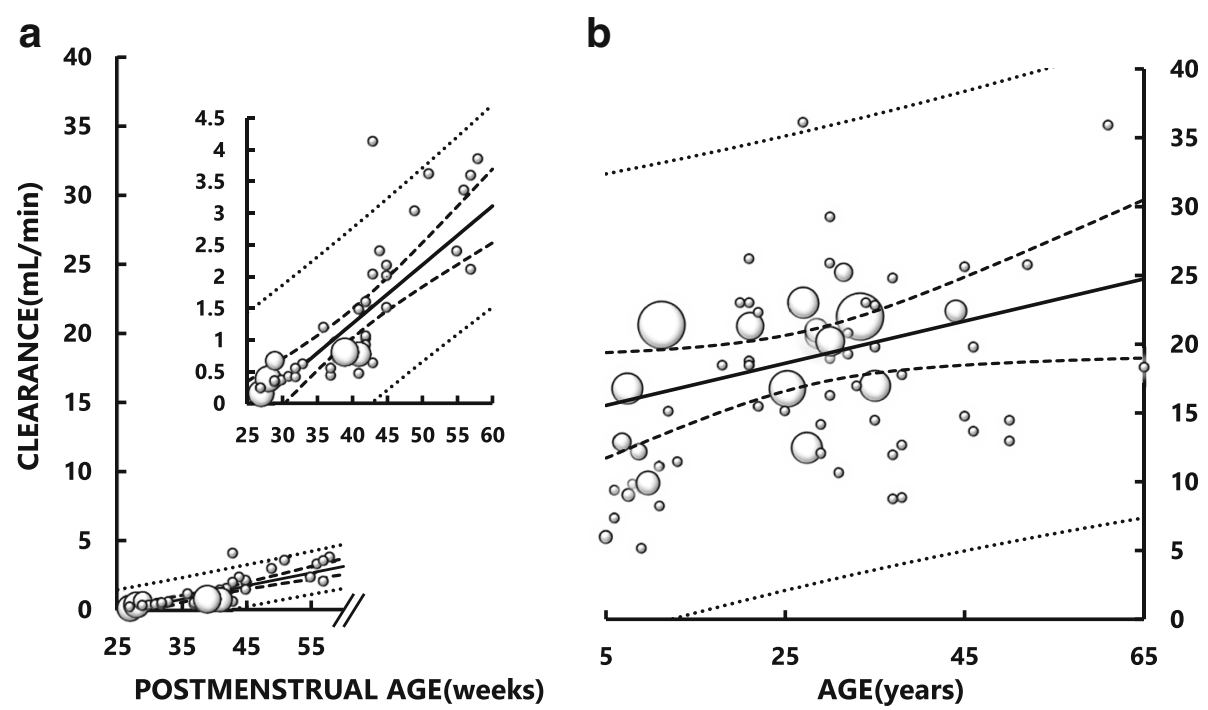

Fig. 1 Relationship between systemic fluconazole clearance $(C L)$ and postmenstrual age (PMA) in neonates and infants (a) and between fluconazole $\mathrm{CL}$ and age in children aged older than 5 years and adults $(\mathbf{b})$. In the inset of A, the data in infants are plotted on a magnified ordinate scale for better visibility. The area of each symbol (o) is in proportion to the number of dataset. There is a significant correlation between fluconazole $C L$ and PMA in infants $(Y=0.093 X-2.45, r=0.81, p<0.001)$, and between fluconazole $C L$ and age in young children and adults $(Y=0.154 X+14.74, r=0.36, p<0.005)$. Solid lines represent the least square regression lines. Bold dotted lines represent the upper and lower $95 \%$ confidence intervals of the regression lines. Fine dotted lines represent the $95 \%$ confidence intervals of the datasets. Note that the scales of the abscissae are different in (a) and (b). No data were available for children aged between PMA 60 weeks and 5 years
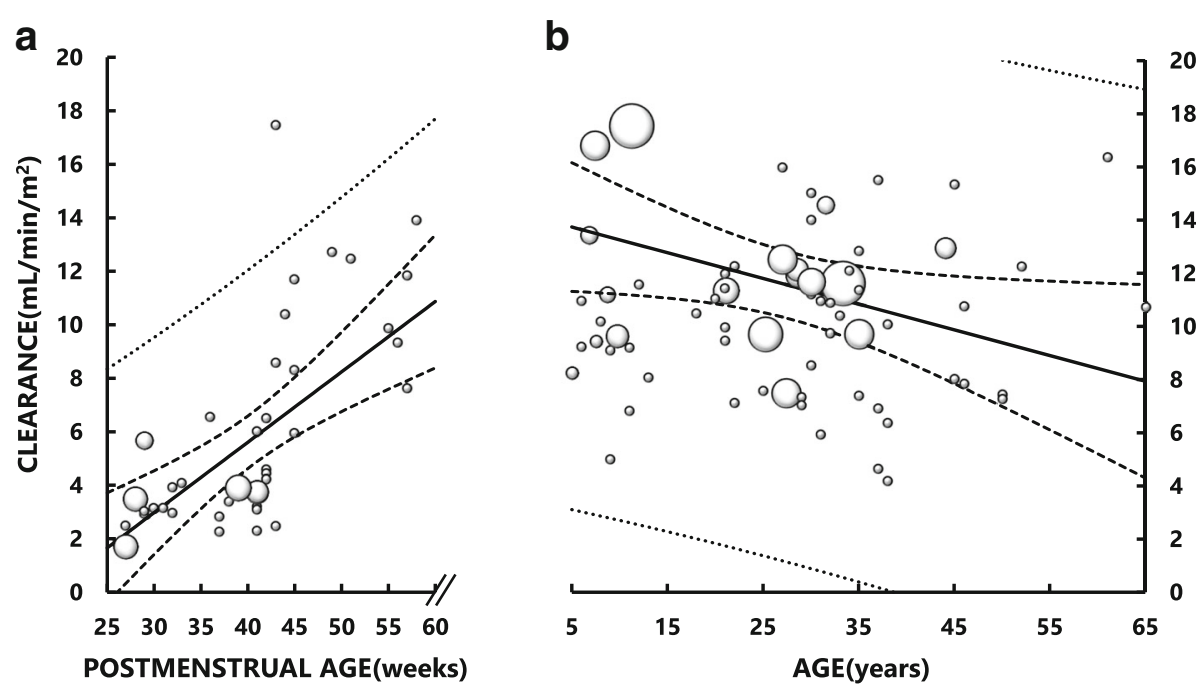

Fig. 2 Relationship between fluconazole clearance normalized to body surface area (BSA) (CL $\left.L_{B S A}\right)$ and postmenstrual age (PMA) in neonates and infants (a) and between fluconazole CLBSA and age in children older than 5 years and adults (b). The area of each symbol (o) is in proportion to the number of dataset. BSA of premature infants and neonates was estimated by Haycock's formula, and that of children and adults by Dubois's formula. There is a significant correlation between fluconazole $C_{\text {BSA }}$ and PMA in neonates and infants $(Y=0.263 X-4.92, r=0.68, p<0.001)$, and between fluconazole $\mathrm{CL}_{\mathrm{BSA}}$ and age in young children and adults $(Y=-0.097 \mathrm{X}+14.22, r=-0.36, p<0.005)$. Solid lines represent the least square regression lines. Bold dotted lines represent the upper and lower $95 \%$ confidence intervals of the regression lines. Fine dotted lines represent the $95 \%$ confidence intervals of all datasets 

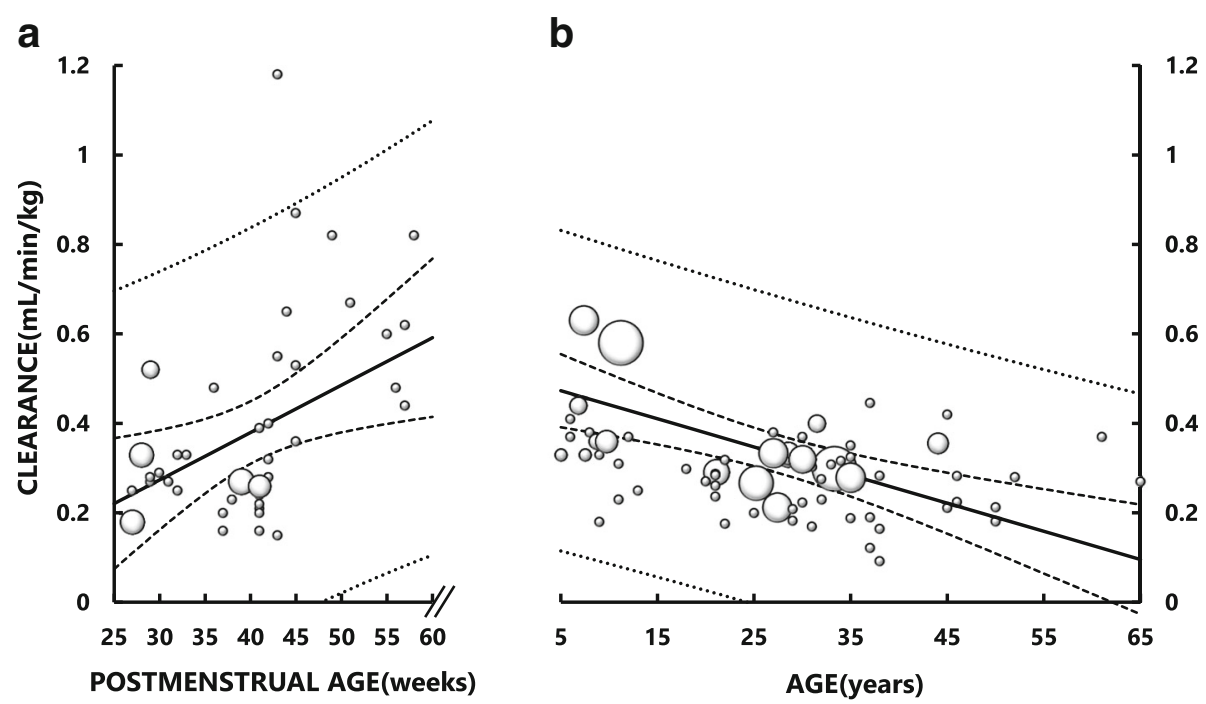

Fig. 3 Relationships between fluconazole clearance normalized to body weight (BW) ( $C_{B W}$ ) and postmenstrual age (PMA) in neonates and infants (a) and between fluconazole $C_{B W}$ and age in children older than 5 years and adults (b). The area of each symbol (o) is in proportion to the number of datasets. There is a significant correlation between fluconazole $C L_{B W}$ and PMA in neonates and infants $(Y=0.011 X-0.04, r=0.46$, $p<0.005)$, and between fluconazole $C_{B W}$ and age in young children and adults $(Y=-0.006 \mathrm{X}+0.50, r=-0.60, p<0.001)$. Solid lines represent the least square regression lines. Bold dotted lines represent the upper and lower $95 \%$ confidence intervals of the regression lines. Fine dotted lines represent the $95 \%$ confidence intervals of all datasets

unadjusted fluconazole CL and size-adjusted fluconazole $\mathrm{CL}\left(\mathrm{CL}_{\mathrm{BSA}}\right.$ and $\left.\mathrm{CL}_{\mathrm{BW}}\right)$ as a function of PMA in neonates and infants (Figs. 1, 2 and 3). Particularly, $\mathrm{CL}_{\mathrm{BSA}}$ in neonates was substantially lower than adult value but increased rapidly after birth reaching the level of adults at approximately PMA 60 weeks (Fig. 2a). These data suggest that the development of fluconazole CL may be attributed not only to an increase in size of body (and organs associated with the elimination of fluconazole) but also to functional maturation of the organ(s) which is associated with elimination of fluconazole. Since fluconazole is eliminated mainly by the kidneys, our data imply rapid and substantial maturation in nephron function in these pediatric subjects. Our notion may be supported by the findings that GFR $_{\mathrm{BSA}}$ also increased rapidly after birth, reaching a plateau that is largely comparable to adult levels by PMA 100 weeks (approximately age 1.5 years) (Fig. 4). Our data thus indicate that
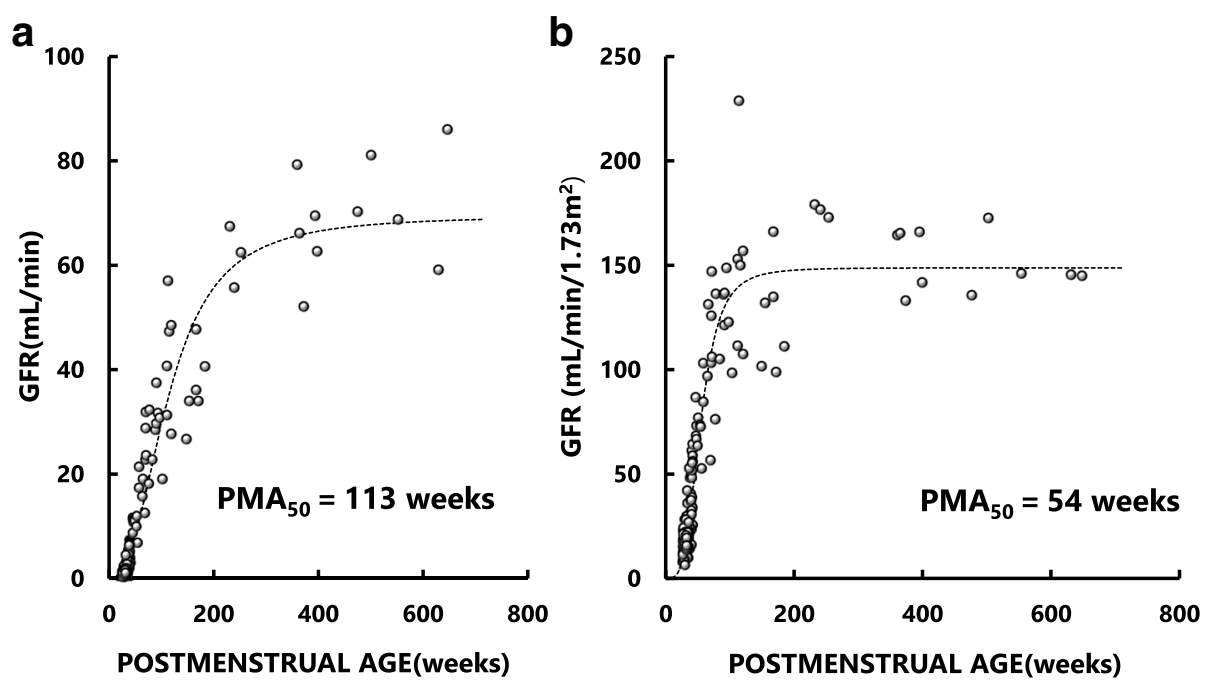

Fig. 4 Developmental time courses of unadjusted glomerular filtration rate (GFR) (a) and GFR normalized to body surface area (BSA) of $1.73 \mathrm{~m}^{2}$ $\left(G_{B S A}\right)(\mathbf{b})$ as a function of PMA in neonates, infants, and children. The original datasets were retrieved from the reports of Rubin et al. (40), Coulthard et al. (42), Fawer et al. (41) and van der Heijden et al. (43). Details of the sigmoidal hyperbolic model are described in the text 


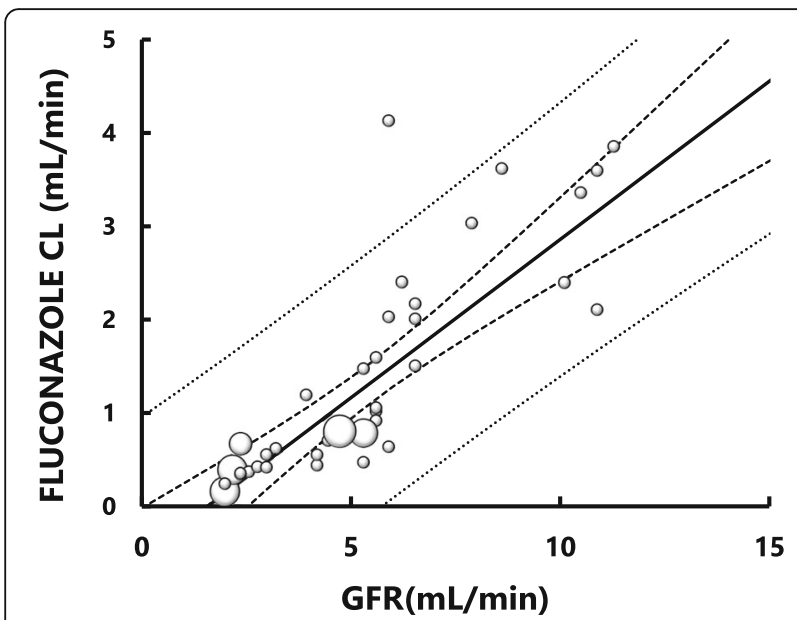

Fig. 5 Relationship between fluconazole clearance $(\mathrm{CL})(\mathrm{mL} / \mathrm{min})$ and glomerular filtration rate (GFR) $(\mathrm{mL} / \mathrm{min})$ in neonates and infants younger than PMA 60 weeks. The area of each symbol (o) is in proportion to the number of datasets. Bold solid line shows the regression line of the data. Bold dotted lines show the upper and lower limits of $95 \%$ confidence intervals of the regression line. Fine dotted lines show the upper and lower 95\% confidence intervals for the datasets. A significant correlation is observed: $Y=0.34 X-0.53$, $r=0.84(p<0.001)$

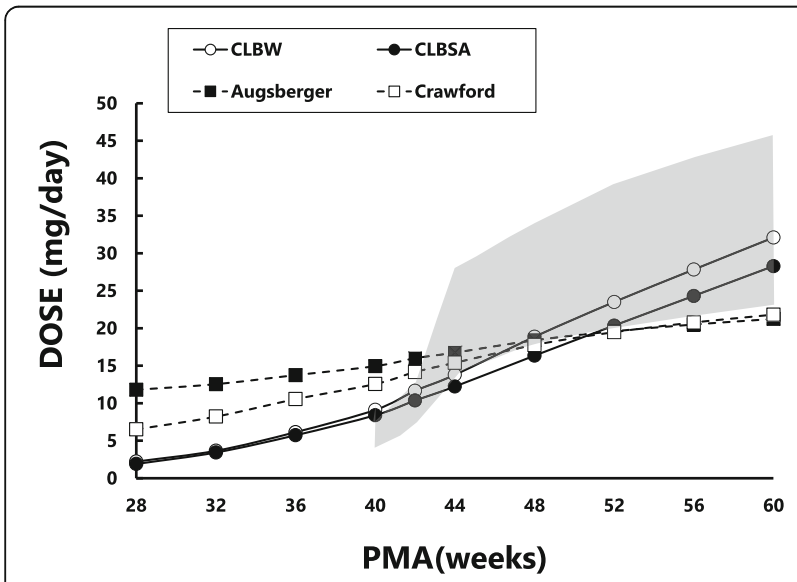

Fig. 6 Comparisons of fluconazole doses for neonates and infants estimated using various formulas for children at PMA ranging from 28 to 60 weeks. Open (o) and closed circles $(\bullet)$ connected with solid lines represent doses predicted by fluconazole clearance normalized to body weight $\left(\mathrm{CL}_{\mathrm{BW}}\right)$ and fluconazole clearance normalized to body surface area $\left(\mathrm{CL}_{\mathrm{BSA}}\right)$, respectively in the present study. Open ( $\square$ ) and closed squares ( $\mathbf{\square}$ ) represent those predicted by the Crawford's and Augsberger's formulas, respectively. The shaded area represents doses calculated according to the recommended doses for treating systemic candidiasis for children (3 to $6 \mathrm{mg} / \mathrm{kg}$ / day) in the latest prescribing information [3] doses of fluconazole for children younger than 2 years should not be estimated simply from usual adult doses using BSA or BW as size-scaling factors, but should be estimated taking into account the development of fluconazole CL in association with functional maturation of nephrons (i.e., $\mathrm{GFR}_{\mathrm{BSA}}$ ).

We found that $\mathrm{CL}_{\mathrm{BSA}}$ obtained from neonates at PMA younger than 40 weeks was approximately $1 / 4$ to $1 / 3$ of adult values (Fig. 2a), whereas the corresponding $\mathrm{CL}_{\mathrm{BW}}$ appeared largely comparable to adult values (Fig. 3a). A previous study has shown that the developmental time courses of organ size or mass (such as kidneys) and BSA are almost identical [2]. In this context, we surmise that neonates may have substantially immature fluconazole CL per unit kidney mass (i.e., CL normalized to BSA), compared to adults (Fig. 2a and b). Similar findings have been reported for other drugs [44-46]. These findings may be explained by a difference in the developmental time course of body weight and that of organs. The development of body weight has been shown to lag behind that of organ size and BSA [2]. As a result, the ratios of organ mass (such as liver and kidney mass) per body weight in children are greater, maximally two-fold, than those in adults. Consequently, fluconazole $\mathrm{CL}_{\mathrm{BW}}$ in neonates might have been overestimated and thereby appeared similar to that in adults, and fluconazole $\mathrm{CL}_{\mathrm{BW}}$ in infants around PMA 60 weeks and children aged 5 to 10 years might have been overestimated and appear to be greater than that in adults (Fig. 3a and b).

We found that while unadjusted GFR ( $\mathrm{mL} / \mathrm{min}$ ) in neonates were substantially lower than those in adults, GFR increased rapidly as shown by a $\mathrm{PMA}_{50}$ of 113 weeks and appeared to reach a plateau around PMA 600 weeks or age 10 years (Fig. 4a). Rodin et al. [12] reported data being similar to ours and analyzed the curvilinear data with the sigmoidal model. We also adopted the model in the present study. Interestingly, the plateau level $\left(149 \mathrm{~mL} / \mathrm{min} / 1.73 \mathrm{~m}^{2}\right)$ for children was comparable to that of a representative adult male $\left(130 \mathrm{~mL} / \mathrm{min} / 1.73 \mathrm{~m}^{2}\right)$ [47] (Fig. 4b). Since GFR $_{\text {BSA }}$ represents the nephron function per standardized mass of kidney, this finding indicates that neonatal nephron function is very immature at birth but develops rapidly in early childhood reaching almost adult level by around age 2 years. Our findings are supported by previous studies on the ontogeny of renal morphology and physiology. A study has shown that although nephrogenesis is complete by 36 weeks of gestation, neonatal GFR is only approximately $5 \%$ of the adult value [48]. Neonatal nephron function is immature due mainly to vasoconstriction of the renal microvasculature, whereas the postnatal increase in renal mass is due almost entirely to tubular growth [48].

Assuming that plasma fluconazole concentrations required for the treatment of systemic fungal infection are comparable between children and adults, and that the 
typical adult dose of the drug is $100 \mathrm{mg} /$ day, it is possible to estimate individual fluconazole doses for neonates or infants from adult doses using fluconazole CL of children as a scaling factor. Since there is good relationships between GFR of neonates and infants and PMA (Fig. 4) and between fluconazole CL and GFR (Fig. 5), fluconazole CM for a neonates and infants may be estimated by PMA. The fluconazole doses for neonates at PMA 40-44 weeks predicted by the two empirical dosing formulas are higher than those estimated using $\mathrm{CL}_{\mathrm{BSA}}$ or $\mathrm{CL}_{\mathrm{BW}}$ and those recommended in the prescribing information. In contrast, the doses estimated using $\mathrm{CL}_{\mathrm{BSA}}$ or $\mathrm{CL}_{\mathrm{BW}}$ were similar to those recommended in the prescribing information for systemic candidiasis (3 to $6 \mathrm{mg} / \mathrm{kg} /$ day). For infants at PMA 44 weeks and older, fluconazole doses predicted by our CL-based methods and the 2 empirical formulas are essentially within the range of doses recommended by the prescribing information.

The present study has some limitations. Since pharmacokinetic studies for children are difficult to conduct, only sparse data and datasets with incomplete clinical information are available from the literature. As a result, we often had to utilize average demographic data from subjects with comparable PMA or mean pharmacokinetic parameters for a group in estimating parameters for individual subjects. In addition, since no pharmacokinetic data were available for children from PMA 60 weeks to age 5 years, we cannot estimate the development of fluconazole CL during this period. Finally, CL-based prediction of fluconazole doses for pediatric patients with fungal infection would only be valid if therapeutic plasma drug concentrations are similar between children and adults. Since neonates and infants are immunologically less competent than older children, whether they need higher fluconazole concentrations than adults for treatment remains to be studied. The reason why $\mathrm{CL}_{\mathrm{BW}}$ and $\mathrm{CL}_{\mathrm{BSA}}$ showed weak, but significant, negative correlations with age (Figs. $2 \mathrm{~b}$ and $3 \mathrm{~b}$ ) are most likely associated with an age-dependent decrease in GFR [49].

\section{Conclusions}

This study reveals that size-normalized fluconazole CL in neonates and infants is substantially lower than that in adults, but fluconazole CL develops rapidly during early childhood. Immature nephron function in neonates and infants may contribute to immature renal clearance for fluconazole. Fluconazole doses for neonates and infants may be estimated by taking into consideration developmental change of $\mathrm{CL}_{\mathrm{BSA}}$ that is associated with the development of GFR.

\begin{abstract}
Abbreviations
BSA: Body surface area; $C L$ : Systemic clearance; $\mathrm{CL}_{\mathrm{BSA}}$ : Clearance normalized to $B S A ; L_{B W}$ : Clearance normalized to body weight; GFR: Glomerular filtration rate; GFR $\mathrm{BSA}_{\mathrm{A}}$ : Glomerular filtration ratio normalized to BSA; GFR $_{B S A \text {,max: }}$ The maximum value for GFR; PMA: Postmenopausal age; PMA $_{50}$ : Postmenopausal age associated with $50 \%$ of the maximum GFR
\end{abstract}

\begin{abstract}
Acknowledgements
Not applicable.

Funding

The present study was supported by a grant-in-aid of Meiji Pharmaceutical University.

Availability of data and materials

The datasets generated and analyzed during the present study were obtained from publicly available databases of MEDLINE and Japan Medical Abstracts Society.
\end{abstract}

\section{Authors' contributions}

$\mathrm{KM}, \mathrm{RM}$, and HE contributed to the study conception and design. KM was involved in data collection. KM and HE were involved in analysis of data. KM drafted the manuscript, and RM and HE critically revised the manuscript. All authors read and approved the final manuscript.

\section{Ethics approval and consent to participate}

Because the present study was conducted by analyzing publicly available data, neither ethics approval nor consent to participate were applicable.

\section{Consent for publication}

Not applicable.

\section{Competing interests}

All authors declare that they have no competing interests.

\section{Publisher's Note}

Springer Nature remains neutral with regard to jurisdictional claims in published maps and institutional affiliations.

Received: 4 December 2017 Accepted: 5 March 2018

Published online: 20 March 2018

References

1. Kearns $G L$, et al. Developmental pharmacology-drug disposition, action, and therapy in infants and children. N Engl J Med. 2003:1157-37.

2. Anderson BJ, Holford NH. Understanding dosing: children are small adults, neonates are immature children. Arch Dis Child. 2013;98:737-44.

3. Prescribing information: Diflucan ${ }^{\circledast}$ intravenous solution $50 \mathrm{mg}, 100 \mathrm{mg}$ and 200 mg, Pfizer Japan Inc., 2017 [in Japanese].

4. Old AA. New rules for dosage determination in paediatrics. Triangle. 1962; 5:200-7.

5. Crawford JD, Terry ME, Rourke GM. Simplification of drug dosage calculation by application of the surface area principle. Pediatrics. 1950;5:783-90.

6. Brammer KW, Farrow PR, Faulkner JK. Pharmacokinetics and tissue penetration of fluconazole in humans. Rev Infect Dis. 1990;12(Suppl 3):S318-26.

7. Centers for Disease Control and Prevention National Center for Health Statistics. https://www.cdc.gov/growthcharts/data/who/GrChrt_Boys_24LW_ 100611.pdf. (Accessed 9 Mar 2018).

8. Ito Z et al., Standard growth charts for Japanese children in 2000, J Pediatr Pract 2005;7:1343-1351 [in Japanese].

9. Ahn Y. Formula and scale for body surface area estimation in high-risk infants. Coll Antropol 2010;34:1273-1280.

10. Haycock GB, Schwartz GJ, Wisotsky DH. Geometric method for measuring body surface area: a height-weight formula validated in infants, children, and adults. J Pediatr. 1978;93:62-6.

11. DuBois D, DuBois EF. A formula to estimate the approximate surface area if height and weight be known. Arch Intern Med. 1916;17:863-71.

12. Rhodin MM, Anderson BJ, Peters AM, Coulthard MG, Wilkins B, Cole M, et al. Human renal function maturation: a quantitative description using weight and postmenstrual age. Pediatr Nephrol. 2009;24:67-76. 
13. Turner K, Manzoni P, Benjamin DK, et al. Fluconazole pharmacokinetics and safety in premature infants. Curr Med Chem. 2012;19:4617-20.

14. Saxen H, Hoppu K, Pohjavuori M. Pharmacokinetics of fluconazole in very low birth weight infants during the first two weeks of life. Clin Pharmacol Ther. 1993;54:269-77.

15. Krzeska I, Yeates RA, Pfaff G. Single dose intravenous pharmacokinetics of fluconazole in infants. Drugs Exp Clin Res. 1993;19(6):267-71.

16. Kondo M, Itoh S, Isobe K, Kawada K, Sumitani T, Ishii M, et al. Pharmacokinetic evaluation of fluconazole in very low birth weight infants. Acta Neonat Jap. 1995;31:885-9.

17. Seki H, Seno A, Sakazume S, Shinoda K, Shintani N, Wada T, et al. Clinical study of fluconazole-injectable and -granules in pediatric patients. Jpn J Antibiot. 1994;47(3):289-95. [in Japanese]

18. Piper L, Smith PB, Hornik CP, Cheifetz IM, Barrett JS, Moorthy G, et al. Fluconazole loading dose pharmacokinetics and safety in infants. Pediatr Infect Dis J. 2011;30:375-8.

19. Wiest DB, Fowler SL, Garner SS, Simons DR. Fluconazole in neonatal disseminated candidiasis. Arch Dis Child. 1991;66:1002.

20. Fujii R, Matsumoto S, Sakiyama Y, Ishikawa Y, Takeda T, Hatae Y, et al. A clinical study of fluconazole-granules and -injectable in pediatric patients with deep-seated mycoses. Jpn J Antibiot. 1993;46:654-85. [in Japanese]

21. Nahata MC, Tallian KB, Force RW. Pharmacokinetics of fluconazole in young infants. Eur J Drug Metab Pharmacokinet. 1999:24:155-7.

22. Wenzl TG, Schefels J, Hörnchen H, Skopnik H. Pharmacokinetics of oral fluconazole in premature infants. Eur J Pediatr. 1998;157:661-2.

23. Sato Y, Iwata S, Akita H, Kobayashi M, Yokota T, Sunakawa K. Pharmacokinetic and Clinical studies on fluconazole in the pediatric field. Jpn J Antibiot. 1994;47:272-9.

24. Lee JW, Seibel NL, Amantea M, Whitcomb P, Pizzo PA, Walsh TJ. Safety and pharmacokinetics of fluconazole in children with neoplastic diseases. J Pediatr. 1992;120:987-93.

25. Seay RE, Larson TA, Toscano JP, Bostrom BC, O'Leary MC, Uden DL. Pharmacokinetics of fluconazole in immune-compromised children with leukemia or other hematologic diseases. Pharmacotherapy. 1995:15:52-8.

26. Nahata MC, Brady MT. Pharmacokinetics of fluconazole after oral administration in children with human immunodeficiency virus infection. Eur J Clin Pharmacol. 1995;48:291-3.

27. Shiba K, Saito A, Safety MT. Pharmacokinetics of single oral and intravenous doses of fluconazole in healthy subjects. Clin Ther. 1990;12:206-15.

28. Ripa S, Ferrante L, Prenna M. Pharmacokinetics of fluconazole in normal volunteers. Chemotherapy. 1993;39:6-12.

29. Takebe $M$, Tamashige $M$, Nakajima J, Narita $Y$, Uchida $Y$, Takahashi $H$, et al. Pharmacokinetic evaluation of fluconazole - clinical study of the relations between blood and saliva concentration. Jpn J Oral Therpeut Pharamacol. 1991;10:62-6.

30. Humphrey MJ, Jevons S, Tarbit MH. Pharmacokinetic evaluation of UK49,858, a metabolically stable triazole antifungal drug, in animals and humans. Antimicrob Agents Chemother. 1985;28:648-53.

31. Thorpe JE, Baker N, Bromet-Petit M. Effect of oral antacid administration on the pharmacokinetics of oral fluconazole. Antimicrob Agents Chemother. 1990;34:2032-3.

32. Toon S, Ross CE, Gokal R, Rowland M. An assessment of the effects of impaired renal function and haemodialysis on the pharmacokinetics of fluconazole. Br J Clin Pharmacol. 1990;29:221-6.

33. Jovanović D, Kilibarda V, Cirić B, Vucinić S, Srnić D, Vehabović M, et al. A randomized, open-label pharmacokinetic comparison of two oral formulations of fluconazole $150 \mathrm{mg}$ in healthy adult volunteers. Clin Ther. 2005;27:1588-95.

34. Yeates RA, Ruhnke M, Pfaff G, Hartmann A, Trautmann M, Sarnow E. The pharmacokinetics of fluconazole after a single intravenous dose in AIDS patients. Br J Clin Pharmacol. 1994;38:77-9.

35. Tett S, Moore S, Ray J. Pharmacokinetics and bioavailability of fluconazole in two groups of males with human immunodeficiency virus (HIV) infection compared with those in a group of males without HIV infection. Antimicrob Agents Chemother. 1995;39:1835-41.

36. DeMuria D, Forrest A, Rich J, Scavone JM, Cohen LG, Kazanjian PH. Pharmacokinetics and bioavailability of fluconazole in patients with AIDS. Antimicrob Agents Chemother. 1993;37:2187-92.

37. Chin T, Fong IW, Vandenbroucke A. Pharmacokinetics of fluconazole in serum and cerebrospinal fluid in a patient with AIDS and cryptococcal meningitis. Pharmacotherapy. 1990;10:305-7.
38. Houang ET, Chappatte O, Byrne D, Macrae PV, Thorpe JE. Fluconazole levels in plasma and vaginal secretions of patients after a 150-milligram single ora dose and rate of eradication of infection in vaginal candidiasis. Antimicrob Agents Chemother. 1990;34:909-10.

39. Boucher BA, King SR, Wandschneider HL, Hickerson WL, Hanes SD, Herring $\mathrm{VL}$, et al. Fluconazole pharmacokinetics in burn patients. Antimicrob Agents Chemother. 1998;42:930-3.

40. Rubin MI, Bruck E, Rapoport M, Snively M, McKay H, Baumler A. Maturation of renal function in childhood: clearance studies. J Clin Invest. 1949;28: 1144-62.

41. Fawer $\mathrm{CL}$, Torrado A, Guignard JP. Maturation of renal function in full-term and premature neonates. Helv Paediatr Acta. 1979;34:11-21.

42. Coulthard MG. Maturation of glomerular filtration in preterm and mature babies. Early Hum Dev. 1985;11:281-92.

43. van der Heijden AJ, Grose WF, Ambagtsheer JJ, Provoost AP, Wolff ED, Sauer PJ. Glomerular filtration rate in the preterm infant: the relation to gestational and postnatal age. Eur J Pediatr. 1988;148:24-8.

44. Murry DJ, Crom WR, Reddick WE, et al. Liver volume as a determinant of drug clearance in children and adolescents. Drug Metab Dispos. 1995;23: 1110-6.

45. Takahashi H, Ishikawa S, Nomoto S, et al. Developmental changes in pharmacokinetics and pharmacodynamics of warfarin enantiomers in Japanese children. Clin Pharmacol Ther. 2000;68:541-55.

46. Johnson TN, Rostami-Hodjegan A, Tucker GT. Prediction of the clearance of eleven drugs and associated variability in neonates, infants and children. Clin Pharmacokinet. 2006:45:931-56.

47. Wesson LG, Wesson LG. Renal hemodynamics in physiologic states, Physiology of the Human Kidney. New York: Grune \& Stratton; 1969. p. 96-108.

48. Haycock GB. Development of glomerular filtration and tubular sodium reabsorption in human fetus and newborn. Brit J Urol. 1998;81(suppl.2):33-8.

49. Weinstein JR, Anderson D. The aging kidney: physiological changes. Adv Chronic Kidney Dis. 2010;17:302-7.

\section{Submit your next manuscript to BioMed Central and we will help you at every step:}

- We accept pre-submission inquiries

- Our selector tool helps you to find the most relevant journal

- We provide round the clock customer support

- Convenient online submission

- Thorough peer review

- Inclusion in PubMed and all major indexing services

- Maximum visibility for your research

Submit your manuscript at www.biomedcentral.com/submit

) BioMed Central 